Revista Educação e Políticas em Debate - v. 7, n. 3, p. 576-596, set./dez. 2018 - ISSN 2238-834

\title{
Docência Universitária: a profissionalização docente em cursos da área da saúde no contexto pós-neoliberal
}

\author{
University Teaching: the professionalization in health courses in post-neoliberal context \\ Enseignement universitaire: la professionnalisation de l'enseignement dans les cours du \\ domaine de la santé dans le contexte post-néolibéraux
}

Silvana Malusá ${ }^{1}$

Universidade Federal de Uberlândia

João Wilson Savino Carvalho ${ }^{2}$

Universidade Federal do Amapá

Ana Claudia J. P. de Medeiros ${ }^{3}$

Universidade Federal de Uberlândia

Luciana Charão de Oliveira ${ }^{4}$ Universidade Federal de Uberlândia

André Sanches Siqueira Campos ${ }^{5}$ Universidade Federal de Uberlândia

Resumo: O desenvolvimento profissional dos professores tem sido objeto de propostas educacionais que valorizam uma formação docente não mais baseada na racionalidade técnica, mas em uma perspectiva que reconhece a capacidade desses profissionais de decidir, de confrontar suas ações cotidianas com as produções teóricas, em especial num período pósneoliberal que se encontram. Diante dessa reflexão, o objetivo deste trabalho - de natureza aplicada e exploratória, valorizando e explorando as abordagens quantitativa e qualitativa é o de compreender a profissionalização do professor universitário no contexto pósneoliberal e seus impactos nas suas práticas e saberes, tendo como referência as percepções dos profissionais docentes na área da saúde. Fruto de uma pesquisa maior, o instrumento de trabalho aqui utilizado foi aprovado pelo Comitê de Ética em Pesquisa - CEP/UFU, sob o protocolo de registro 043/11.

\footnotetext{
${ }^{1}$ Professora Associada IV da Universidade Federal de Uberlândia (UFU). Doutora e Pós-doutora em Educação Coordenadora Pedagógica DINTER/UFU/UFPI. Coordenadora do Grupo de Pesquisa Desenvolvimento profissional e docência universitária: saberes e práticas educativas. E-mail: silmalusa@yahoo.com.br

2 Doutor em educação. Professor Associado da Universidade Federal do Amapá (UNIFAP). Graduado em Filosofia, Psicologia e Direito. Especialista em Educação de Adultos (UFPB;PPGED/UFU). E-mail: wilsoncarvalho@unifap.br

3 Doutoranda do Programa de Pós-Graduação em Educação da Faculdade de Educação da Universidade Federal de Uberlândia (PPGED/UFU).E-mail: anaclaudiaufu@yahoo.com.br

4. Doutoranda do Programa de Pós-Graduação em Educação da Faculdade de Educação da Universidade Federal de Uberlândia (PPGED/UFU).E-mail :luciana.admufu@gmail.com

5 Doutorando em Relações Internacionais pelo Programa de Pós-Graduação San Tiago Dantas (UNESP, UNICAMP, PUC-SP). Mestrado em Relações Internacionais com área de concentração em Política Internacional pelo Instituto de Economia da Universidade Federal de Uberlândia (IE UFU). E-mail: andresanches41@gmail.com.
} 
Palavras-chaves: Docência Universitária; Formação Docente; Docente no PósNeoliberalismo.

\begin{abstract}
The professional development of teachers has been the subject of educational proposals that value a teacher training no longer based on technical rationality, but from a perspective that recognizes the ability of these professionals to decide to confront their daily actions with theoretical productions, especially in a period post-neoliberal they are. Faced with this reflection, the aim of this work - of applied and exploratory nature, appreciating and exploring the quantitative and qualitative approaches - is to understand the professionalization of university teaching in the post-neoliberal context and its impact on practices and knowledge of academics, with reference to the perceptions of teaching professionals in the health field. The result of a larger research work instrument used herein was approved by the Research Ethics Committee (CEP / UFU) under the registration protocol $043 / 11$.
\end{abstract}

Keywords: University teaching. Teacher Training. Lecturer in Post-Neoliberalism

Résumé: Le développement professionnel des enseignants a fait l'objet de propositions éducatives qui valorisent la formation des enseignants non plus sur la rationalité technique, mais dans une perspective qui reconnaît la capacité de ces professionnels à décider et à confronter leurs actions quotidiennes avec des productions théoriques, en particulier dans une période post-néolibéraux qui se trouvent. Face à cette réflexion, l'objectif de cet article scientifique - de nature appliquée et exploratoire, valorisant les approches quantitatives et qualitatives - est de comprendre la professionnalisation du professeur d'université dans le contexte post-néolibéraux et ses impacts sur ses pratiques et ses connaissances, en se référant aux perceptions des professionnels de l'enseignement dans le domaine de la santé. Dérivé d'une recherche plus large, l'outil de travail utilisé ici a été approuvé par le comité d'éthique de la recherche - CEP/UFU, conformément au protocole d'enregistrement $043 / 11$.

Mots clés: Enseignement universitaire. Formation des enseignants. Enseignant en postnéolibéralisme.

Recebido em: 08 de outubro de 2018

Aceito em: 20 de dezembro de 2018

\title{
1 Introdução
}

Não são poucos os estudiosos que vêm apontando a escola como lócus privilegiado à formação e ao desenvolvimento profissional do professor. Nesse aspecto, as universidades têm sido lentas e resistentes para incentivar seu corpo docente ao reconhecimento e importância de uma "Pedagogia Universitária" como campo de produção de conhecimento.

Algumas iniciativas reconhecem movimentos que se preocupam com os saberes próprios para o exercício da profissão do professor do ensino superior. No entanto, são 
movimentos ainda distantes da maioria dos professores, uma vez que não há reconhecimento oficial da legitimidade desses saberes pedagógicos. Percebemos, nessa realidade, que o problema sobre a formação do docente universitário envolve grandes questões, desde dúvidas sobre qual é a função dele, "passando pela discussão sobre qual a natureza dessa profissão e dos processos formativos que a constitui, envolvendo a concepção de professoralidade, que tem por pressuposto básico o conhecimento pedagógico compartilhado” (ISAÍA; BOLSAN, 2009, p.163).

Diante dessa breve reflexão, este trabalho tem como objetivo central o de compreender a profissionalização do docente universitário no contexto pós-neoliberal e seus impactos nas práticas e saberes dele, tendo como referência as percepções dos profissionais docentes na área da saúde.

\section{A formação profissional docente no cerne dos contextos neoliberal e pós-neoliberal}

O objetivo da primeira etapa deste artigo é caracterizar o contexto neoliberal e pósneoliberal. Para tal, analisamos de que forma as políticas educacionais para a profissionalização docente são conduzidas nesse processo. Também são evidenciados os pontos de continuidade, ruptura e de inserção profissional forçada pela economia da “indústria” da educação ou voluntária, mediante a percepção do papel social e político do profissional docente, no início do século XXI, período constatado como um momento de transição do pensamento neoliberal para uma ideologia pós-neoliberal.

No plano nacional, os debates em torno do contexto, no qual a formação profissional docente se insere, estiveram entremeados à luz das políticas educacionais cujas visões e interpretações foram influenciadas pela intensificação do movimento de globalização. Esse movimento viabiliza a disseminação das normas e diretrizes de viés predominantemente neoliberal, elaboradas pelos organismos internacionais.

Os autores Tello e Almeida (2014) estabelecem uma relação entre o papel dos organismos internacionais e a forma como as agendas de políticas da globalização neoliberal são constituídas. Eles preconizam que, assim como os organismos internacionais podem assumir uma determinada ortodoxia, ela pode ser constituída como um ponto de equilíbrio e inflexão perante as ortodoxias exógenas. Isso garante que determinado grupo possa analisar e gerar uma nova ortodoxia a partir de uma perspectiva endógena. 
Sob essa perspectiva, a modernização da educação é identificada com a profissionalização e a diminuição do papel do Estado, a partir das condicionalidades provenientes de instituições como o Banco Mundial (BM), Fundo Monetário Internacional(FMI) e o Banco Interamericano de Desenvolvimento (BID). Esses organismos enfatizam suas recomendações de política educacional e impõem uma 'nova ortodoxia', baseada em um controle mais direto sobre o curriculum e a avaliação docente, na redução dos custos em educação por parte dos governos e em uma pressão dos 'clientes' em termos de uma escola gerencialista, ou seja, trata-se de uma visão neoliberal direcionada às políticas em educação.

A formação profissional docente se configura e é moldada segundo a preponderância do contexto sócio-político-econômico no qual o indivíduo está inserido. Ainda segundo Tello e Almeida (2014), o fenômeno da globalização despertou novas dinâmicas entre os atores públicos e privados e revela o cenário em que as políticas de profissionalização docente estão inseridas.

Com a globalização, o entrelaçamento das estratégias de empresas com o Estado, em torno do conhecimento e políticas governamentais, tornou-se ainda mais fundamental da defesa dos interesses do capital. Isso tem sido decisivo para a supremacia de alguns centros decisórios do capitalismo. (TELLO; ALMEIDA, 2014, p. 163)

Os autores complementam esse cenário ao afirmar que a prática científica está associada a uma luta de classes, fragmentadas pela perspectiva marxista e pós-moderna, cujo "pano de fundo" ampara as discussões em torno do papel da formação docente.

Num primeiro prisma, estariam visões "fragmentaristas", no outro, as visões "integradoras". Onde uma vê ruptura e "esgarçamento" contínuo e irremediável da realidade, a outra vê continuidade e totalização que se está constituindo. Do ponto de vista político, a primeira não acredita na possibilidade de uma ação centralizada, tal como propõem os defensores do planeamento estatal. A outra perspectiva, pelo contrário, nega a possibilidade de uma "autodeterminação" espontânea de uma série de agentes atuando conforme os seus fins particulares. (TELLO; ALMEIDA, 2014, p.163)

Dessa maneira, verifica-se que as ideias relacionadas ao "acesso, equidade, qualidade, massificação, privatização e mercantilização” (AGUIAR, 2016, p. 113) são os conceitos norteadores da formulação política responsável por determinar o perfil do profissional docente que atuará nas instituições de ensino superior. Contudo, são ideias que oscilam entre 
a retórica e a prática, não representando um cenário com vistas a convergir em uma formação docente que atenda às reais necessidades da educação e aos anseios da sociedade.

Segundo Tello e Mainardes (2015), é possível caracterizar, com maior clareza, o contexto neoliberal em relação ao período pós-neoliberal:

[...] o neoliberalismo pode ser identificado em políticas e programas implementados a partir da década de 1990, mas cujo processo iniciou-se na década de 1960, com a implementação de políticas desenvolvimentistas na América Latina. Por outro lado, o pós-neoliberalismo é ainda recente e necessita de uma compreensão mais aprofundada. (TELLO; MAINARDES, 2015 , p. 52)

Esses autores observam que a profissionalização docente pode ser analisada sob o prisma da sociologia das profissões, na qual a profissão docente ainda se encontra em processo de definição. Por outro lado, segundo a perspectiva pedagógico-didática, a profissionalização docente é compreendida como o desenvolvimento profissional do indivíduo que ingressa em uma instituição educacional, na qual desempenha seu exercício profissional e atravessa a formação contínua.

A formação docente está inserida no âmbito das políticas educativas e, por isso, os contextos neoliberal e pós-neoliberal são elementos-chave para compreender a construção das diretrizes educacionais do Brasil e, consequentemente, analisar como a profissionalização docente é construída.

Algumas alternativas para as políticas neoliberais foram discutidas no Foro de São Paulo (FSP), uma conferência de partidos políticos de esquerda, criada em 1990 a partir de um seminário internacional promovido pelo Partido dos Trabalhadores (PT) do Brasil na América Latina. Além de discutir alternativas, o FSP teve como propósito promover a integração regional no âmbito político, econômico e cultural, sendo voltado para a construção de novas políticas sociais, desvinculadas do ideário neoliberal. A importância do FSP encontra-se no fato de que as concepções defendidas por ele tiveram reflexo nas eleições presidenciais posteriores e tal fato levou à ascensão política de partidos de esquerda nos governos sul-americanos,

Na América Latina, ao participarem de um sistema de disputa eleitoral democrático, os atuais partidos de esquerda buscaram construir modelos políticos diferentes do tradicional modelo inspirado na socialdemocracia europeia. Nesse sentido, a ascensão dos governos pósneoliberais representou uma postura de reflexão do papel a ser desenvolvido pelo Estado na 
economia e na política, proporcionando uma revisão das estratégicas políticas domésticas e internacionais.

Foi diante de um ambiente instaurado Pós-Consenso de Washington ${ }^{\mathrm{i}}$ e mediante a fraca solidez das reformas neoliberais empreendidas nos últimos anos que a agenda de desenvolvimento se fortaleceu no Brasil, ou seja, essa formulação política se mostrou como uma alternativa viável para superar o cenário de crise instaurado, ao configurar uma conjuntura com vistas à redução da pobreza, da desigualdade econômica e da inclusão social.

Dessa maneira, esse modelo, também denominado "neodesenvolvimentista", dá ao Estado a capacidade de promoção da estabilidade econômica, afastando a ideia de predomínio do mercado para determinar os rumos do desenvolvimento. Contudo, Cervo (2014) afirma que a trajetória do papel do Estado oscilou entre a presença proeminente do pensamento desenvolvimentista, o afastamento ilusório do neoliberalismo e o papel da associação entre Estado e sociedade, sendo esse o paradigma de política externa atribuído com maior ênfase aos governos pós-neoliberais. Nesse contexto:

O Brasil, país de conciliação neoliberal concebe as políticas públicas mais próximas a busca do bom capitalismo. O Estado ao assumir sua posição de indutor do desenvolvimento, assume nova estrutura matriz vinculada à orientação e impulso estratégico do setor público e da atividade privada buscando alcançar convergências nos objetivos nacionais entre os setores, isso não implica substituição pelo setor privado. Bresser-Pereira refere-se ao novo desenvolvimentismo. (TELLO; MAINARDES, 2015, p. 37)

No Brasil, as escolhas políticas pós-neoliberais do governo Lula da Silva (2003-2010) e de Dilma Rousseff I (2011-2014) representaram uma forte mudança na postura e no papel desempenhado pelo Estado com relação ao modelo político praticado pelos governos neoliberais de Fernando Collor, Itamar Franco e Fernando Henrique Cardoso. Em Sader (2013) e Cervo (2008) observam-se os caminhos predominantes que os governos pósneoliberais tomaram nesse marco temporal: 1) Priorizam-se as políticas sociais e não o ajuste fiscal; 2) Priorizam-se os processos de integração regional e as coalizões Sul-Sul e não os tratados de livre comércio com os Estados Unidos; 3) Prioriza-se o papel do Estado como indutor do crescimento econômico e da distribuição de renda, em vez do Estado mínimo e da centralidade do mercado (SADER, 2013, p. 138; CERVO, 2008, p. 88-90; 2015, p.529).

Ampliou-se a concentração política, econômica e comercial entre os países sulamericanos de modo a constituir um novo bloco regional nomeado, inicialmente, por Comunidade Sul-Americana de Nações e, posteriormente, rebatizado como União de Nações Sul-Americanas (Unasul), em 2008, instituição intergovernamental que integra duas uniões 
aduaneiras existentes na região - o Mercado Comum do Sul (Mercosul) e a Comunidade Andina de Nações (CAN) -, visando um contínuo processo de integração sul-americana. Criou-se em 2012, no âmbito da Unasul, o Conselho Sul-Americano de Educação (CSE), responsável por políticas que promovam o direito de acesso à educação como bem público em todos os níveis educacionais, o intercâmbio técnico de conhecimentos, experiências e capacitação de recursos humanos que estimulem a construção de uma sociedade democrática, respeitando a igualdade de oportunidades e a diversidade cultural.

A sua estrutura é composta por um Conselho de Ministros e Ministras de Educação, uma instância executiva e grupos de trabalhos técnicos. No espectro do CSE, desenvolveu-se o Plano Estratégico 2014-2018, amparado por três eixos integradores, sendo a Qualidade e Equidade; a Cidadania e Direito; Integração Social e Regional, cujo propósito é diagnosticar o sistema educacional dos países sul-americanos e promover uma agenda de trabalho que atenda à realidade regional deles, diminuindo interferências provenientes de uma interpretação de mundo disseminada por uma globalização neoliberal que não corresponde às atuais necessidades sociais e econômicas desses países (BRASIL, 2016). Contudo, Tello e Mainardes (2015) afirmam que o modelo pós-neoliberal ainda não apresenta uma clara desconstrução do modelo neoliberal. Vejamos:

Consideramos que o conceito de "políticas como tradução" (LENDVAI; STUBBS, 2012) pode auxiliar na análise e compreensão crítica da situação atual. Os países latino-americanos têm realizado novas traduções das políticas de globalização neoliberal da década de 1990 na atualidade, a qual pode ser caracterizada como um período pós-neoliberal. O clima pósneoliberal dá-se pela circulação de uma série de discursos políticos em favor da qualidade da educação e do direito à educação, em um contexto em que há promulgação de novas leis de educação (orientadas no âmbito do Mercosul e da Unasul) e em alguns países novas relações são estabelecidas com o Banco Mundial e o Banco Interamericano de Desenvolvimento, em termos de políticas educativas em geral. Neste sentido, devemos considerar que existem diversos modos de instalação e, portanto, de passagens ao pósneoliberalismo, em termos de descontinuidade neoliberal (TELLO; MAINARDES, 2015, p. 51)

Conforme o raciocínio de Tello e Almeida (2014,p.45), não existem indícios claros que caracterizam uma ruptura pós-neoliberal, mas uma "continuidade encoberta do neoliberalismo de 1990", absorvendo as diretrizes de profissionalização docente disseminadas pelos organismos internacionais criados no contexto neoliberal.

Segundo observado em Kimura et. al. (2012, p. 21), foi a partir da percepção da importância do impacto dos aspectos sociais, políticos e econômicos da educação, nos processos de formação humana, que se procurou instituir um modelo que contemplasse a 
formação do profissional docente, com ênfase nos pontos que concernem às melhorias do campo de atuação desse agente da educação, fundamental no processo de democratização da sociedade.

Segundo Tello e Almeida (2014), as políticas públicas dos governos pós-neoliberais no Brasil, além de "respostas à necessidade de gerar igualdade de oportunidade e inclusão social”, representam a ampliação e democratização do acesso à educação por intermédio do viés da equidade, aperfeiçoamento dos instrumentos de avaliação da qualidade do sistema de ensino, incremento da educação à distância com enfoque massificador e limites à expansão de um movimento da privatização educacional, isso por meio da ampliação das vagas em instituições federais de ensino. Contudo, verificou-se uma continuidade no processo de mercantilização das instituições de ensino, pois houve "ausência da regulamentação, quanto à possibilidade de abertura de capital das mantenedoras e à atuação dos fundos de capital nacional e estrangeira", permitindo que a educação superior fosse explorada como uma commodity econômica.

\section{Formação profissional do docente universitário}

A docência nas universidades precisa ser encarada de forma profissional. Partiremos dessa afirmativa para caracterizar como ocorre a formação profissional do docente universitário na contemporaneidade, levando em consideração os contextos neoliberal e pósneoliberal apresentados no tópico anterior.

Podemos dizer que a Lei de Diretrizes e Bases da Educação Nacional nº. 9.394/96 (BRASIL, 1996) configura-se como o principal documento norteador da educação em âmbito nacional e deveria constituir-se o instrumento legal de base para as definições da formação e da função docente.

Corroboramos com a ideia de Batista (2011) para quem a formação do docente no ensino superior não está bem definida na legislação, assim como se encontra nos demais níveis de ensino. Tal fato pode remeter à suposição de que esses professores não tiveram uma formação adequada ou suficiente para a prática docente no ensino superior. A autora afirma, ainda, que o silêncio da legislação em relação à formação do professor universitário tem como consequência algumas dificuldades no que se refere à dimensão didática da profissão. Além disso, a existência da ideia de que a competência do professor universitário advém da área de conhecimento na qual atua, acaba por colocar a formação dele como uma responsabilidade 
individual ou em parceria com os programas de pós-graduação das Instituições de Ensino Superior (BATISTA, 2011).

Importante dizer que a formação do docente não deve ser encarada de forma unilateral, sem compreender as diversas faces que a tornam uma atividade em constante atualização e aprimoramento. $\mathrm{O}$ ensino superior no Brasil, em seus primórdios, teve como inspiração o modelo de ensino francês que supervaloriza as ciências exatas e tecnológicas, desvalorizando a filosofia, a teologia e ciências humanas e, ainda, com a departamentalização de cursos voltados para profissionalização.

Os cursos superiores eram voltados à formação de profissionais para exercerem determinada profissão e os docentes consistiam, geralmente, em profissionais de sucesso. $\mathrm{O}$ perfil do docente universitário requisitado era de um profissional com bacharelado ou formação técnica e que exercesse sua profissão de forma competente. Predominava a crença de que quem sabe, automaticamente sabe ensinar. Essa formação predominou até a década de 1970.

As transformações culturais, sociais, econômicas da atualidade requerem novas concepções de ensino, as quais enfatizam o papel docente como facilitador, orientador e incentivador da aprendizagem, em detrimento de seu antigo papel o qual se resumia em mero "transmissor de conhecimento". Assim, é desejável que o corpo docente seja formado por professores que, além de serem excelentes profissionais, também sejam pesquisadores em suas áreas específicas de conhecimento e desenvolvam uma formação continuada com relação à competência pedagógica. $\mathrm{O}$ profissional precisa repensar sua prática de forma reflexiva, ou seja, precisa rever suas atitudes, aprimorar sua ação e perceber que não se ensina utilizando apenas o conhecimento técnico ou aquele adquirido num curso universitário, num mestrado ou doutorado.

O grande objetivo do ensino superior, em tempos de pós-neoliberalismo, deve ser alterado, fazendo com que a ênfase no ensino seja substituída pela ênfase na aprendizagem que, compreendemos, dotada de uma amplitude muito maior, pois valoriza o ser humano e o desenvolvimento pessoal, das capacidades dos indivíduos na sua totalidade. Ao tomarmos a ênfase na aprendizagem como norteadora do processo, teremos uma alteração do papel dos docentes e dos alunos. Então:

O professor terá substituído seu papel exclusivo de transmissor de informações para o de mediador pedagógico ou de orientador do processo de aprendizagem de seu aluno. Donde sua pergunta agora será: o que meu aluno precisa aprender de todo o conhecimento que tenho e de toda a 
experiência que tenho vivido para que ele possa desenvolver sua formação profissional? (MASETTO, 2003, p. 83)

As transformações em nível global conduziram à consciência de que, para ser um docente universitário, são necessárias algumas competências particulares. Masetto elenca três delas: ser competente em uma determinada área do conhecimento - ter domínio dos conhecimentos básicos de uma área e atualizar-se constantemente; ter domínio na área pedagógica - que corresponde a dos princípios da aprendizagem, compreender a importância da atualização do currículo, valorizar a relação professor-aluno, e ter domínio da tecnologia educacional; compreender que o exercício da dimensão política é imprescindível - o professor deve ter consciência de si e do mundo, e assim viabilizar o desenvolvimento de uma consciência crítica em seus alunos (MASETTO, 2003).

O autor procura destacar ainda que o docente universitário não pode reduzir a sua prática a apenas uma dessas três competências. Ele deve ser capaz de realizar uma conexão entre as três, buscando o sucesso no processo de aprendizagem dos alunos. Vale destacar que a dimensão política é de grande importância dada a consciência crítica e ampla que o docente deve tentar despertar em seus alunos. Tal dimensão não diz respeito a uma doutrinação ou algo parecido, trata-se apenas de fazer com que o aluno entenda seu papel na sociedade enquanto cidadão e, especialmente, enquanto profissional. É preciso que o docente tenha consciência de que a transformação social só será possível mediante a conscientização dos alunos sobre as questões sociais que os rodeiam, lembrando que a questão ética, nesse contexto, representa a legitimidade da profissionalização docente.

É necessário, também, que a formação do docente universitário seja compreendida no âmbito das instituições. Isso corresponde a dizer que o currículo das universidades deve ser elaborado de forma a valorizar todas as dimensões que compreendem a prática docente. Assim:

O ensino superior certamente irá rever seus currículos de formação profissional à luz das novas exigências que estão postas para o exercício competente das profissões em nossa sociedade. A revisão dos novos perfis das várias carreiras, por certo, indicará as alterações curriculares que possam atender melhor às exigências atuais. (MASETTO, 2003, p.18)

As considerações de Masetto (2003) acerca da formação pedagógica do docente recaem sobre o modo como se têm configurado as políticas educacionais para o ensino superior, visando, assim, atender à lógica da nova ordem capitalista de produção. Tal lógica acaba por ter como preocupação maior a adaptação dos currículos e ocasiona perdas de valores construídos historicamente. Então: 
Há muito que fazer, mas é necessário começar por um esforço intencional e sistemático para responsabilizar a instituição pela formação pedagógica de seus professores, ao mesmo tempo, investindo na produção de um conhecimento sobre essa formação e a diferença que ela pode fazer nos processos de ensinar e aprender para formar cidadãos deste país - uma grande tarefa. (MASETTO, 2003, p. 111)

Uma das iniciativas importantes para fomentar esse esforço e responsabilizar a instituição pela formação pedagógica dos docentes é a exigência que pratiquem o estágio, conforme proposto pela Coordenação de Aperfeiçoamento de Pessoal de Nível Superior (Capes), por meio da Portaria 52/2002 em seu artigo $8^{\circ}$, inciso V. Isso representa um importante espaço de formação dos pós-graduandos, contribuindo significativamente na preparação deles para o exercício da profissão. No artigo 17 dessa Portaria são definidos os critérios para o estágio de docência, garantindo o foco na prática docente.

Entretanto, o estágio tem seus limites e, por isso, nem sempre representa um consenso quanto à formação de professores para o ensino superior. Além do mais, restringe a obrigatoriedade do estágio no ensino superior aos alunos bolsistas de pós-graduação. De qualquer forma, tal iniciativa teve início num período em que as políticas de inspiração pósneoliberal começavam a tomar fôlego no cenário brasileiro, sendo nessa relação que a análise deste estudo se encontra apoiada.

Considerando que a Capes é uma agência pública vinculada ao Ministério da Educação e que atua na expansão e consolidação da pós-graduação stricto sensu (mestrado e doutorado) no Brasil, é possível relacionar essa tentativa de incrementar a formação pedagógica dos docentes por meio dos estágios com a possibilidade de ampliar a atuação do poder estatal nos processos de formação do docente universitário. E essa é uma situação que está em conformidade com os princípios pós-neoliberais.

Como os alunos bolsistas representam uma pequena parcela do corpo discente dos cursos de pós-graduação stricto sensu, não se pode interpretar essa política como uma ruptura com os princípios neoliberais. Ao atingir um pequeno número de alunos, reforça a perpetuação da ausência do Estado na regulamentação da formação do docente do ensino superior, representando, pois, um movimento de continuidade no período pós-neoliberal em relação ao período neoliberal. A vivência, que seria propiciada na experiência de estágio, torna-se um mero componente do currículo que é contabilizado em algumas poucas horas em sala de aula e por poucos alunos. Entendemos como uma forma dos alunos bolsistas justificarem a bolsa que estão recebendo e não como uma preocupação das políticas 
educacionais com vistas à formação de um docente que vivencia a prática aliada à teoria, como é o desejável.

A profissão, em tempos de globalização, deve ser analisada enquanto categoria sujeita a mudanças ocorridas nas relações de produção, que requer homens competitivos, dotados de uma multifuncionalidade e de inúmeras competências. Isso equivale a dizer que, assim como toda e qualquer profissão está sujeita à lógica do mercado, a profissão docente também se encontra em tal posição. Dentre as novas funções a serem assumidas pelos professores, encontram-se questões além das pedagógicas, de caráter político-social. Para Facci:

O professor, em muitas ocasiões, é encarado como o "vilão" de todas as mazelas que povoam o espaço intra-escolar, tais como: o descompasso entre objetivos do ensino formalmente estipulados e a 'tarefa' realizada; o fracasso escolar; os problemas de indisciplina e mesmo de violência na escola; as dificuldades de aprendizagem e, ainda, outras problemáticas enfrentadas nas instituições educativas. (FACCI, 2004, p. 21)

A concepção de docente universitário como profissional comporta múltiplas teorizações sobre a prática social e educacional para a sua formação. Facci (2004) destaca a abordagem de Saviani que compreende uma crítica à abordagem tecnicista, voltada à organização racional onde professores e alunos são colocados em segundo plano.

Facci (2004) apresenta as dimensões consideradas por Nóvoa (1995) e Pimenta (1995 para a formação de professores. São as três dimensões descritas que seriam: a dimensão pessoal - aquela que se refere à articulação entre a vida do professor, processos de autoformação e troca de experiências; a dimensão profissional - que é a apropriação dos saberes da educação e da pedagogia e, ainda, a dimensão organizacional - que corresponde à produção da escola concebendo-a como um ambiente educativo, onde o trabalho e a formação façam parte do mesmo processo.

No que se refere ao ambiente de incertezas de um mundo globalizado, no qual os professores têm que se adaptar, Imbernón (2004) é claro ao discorrer em seus estudos sobre a importância da formação continuada tornando os professores capazes de atuar em diferentes contextos e diante dos conflitos. Além da formação pedagógica, científica, caberá aos professores se apropriarem da “[ [...] teoria para organizá-la, fundamentá-la, revisá-la ou combatê-la se preciso for” (IMBERNÓN, 2004, p.69).

Num ambiente de incertezas, o profissional não se depara mais com situações previamente delineadas. Isso significa que os problemas são múltiplos e desordenados, tendo o profissional que desenvolver uma capacidade para enfrentá-los que requer bem mais que o 
conhecimento do problema em si e da estrutura dele. Requer um conhecimento das situações que o originam, assim como improvisações para lidar com fatos inesperados. Esse aspecto faz com que percebamos que a profissão está em constante construção e a definição dos problemas é um processo ontológico.

Cabe aqui mencionar que essa formação continuada do professor deve conferir aos sujeitos condições de trabalhar pelo coletivo, de forma ética e em prol da busca da autonomia do coletivo. É a partir disso que se viabiliza a construção da autonomia da categoria docente.

Ao discutir alguns elementos do movimento de profissionalização, Tardif (2002) aborda a questão dos fundamentos epistemológicos e vale analisar tal perspectiva com foco nas características do conhecimento profissional que ele apresenta. Para o autor, os conhecimentos especializados e o endosso deles por meio dos títulos adquiridos são uma espécie de proteção adquirida pelos profissionais contra aqueles que se aventuram na profissão sem a formação adequada. São conhecimentos pragmáticos voltados para situações concretas e conferem, aos profissionais, a condição de avaliarem seus pares. É importante ainda dizer que o domínio desses conhecimentos não dispensa a autonomia. Assim:

[...] os conhecimentos profissionais exigem sempre uma parcela de improvisação e de adaptação a situações novas e únicas que exigem do profissional reflexão e discernimento para que possa não só compreender o problema como também organizar e esclarecer os objetivos almejados e os meios a serem usados para atingi-los. (TARDIF, 2000, p. 07)

Para esse autor, o fato é que "a perícia profissional perdeu progressivamente sua aura de ciência aplicada para aproximar-se de um saber muito mais ambíguo, de um saber socialmente situado e localmente construído" (TARDIF, 2000, p. 08), daí a necessidade de reconhecimento da dimensão ética da profissão docente.

Ao dedicarmos especial atenção à dimensão ética da profissão docente, estamos nos referindo a relações entre os diversos sujeitos envolvidos. Cabe mencionar as relações entre professores e alunos, entre professores e instituição, entre professores e pais de alunos, dentre outras. Nesse âmbito das relações, vale citar que a profissão docente se constitui mediante essas relações e vai além, pois a dimensão profissional também diz respeito a questões tais como a regulamentação da profissão e a construção da identidade.

Considerando os elementos até aqui expostos e a importância de se pensar a formação do docente universitário no âmbito das práticas cotidianas, faz-se necessário ampliar essas discussões para o chão das universidades, convocando os próprios docentes a participarem dos debates, contribuindo com pesquisas que os levem a refletir sobre suas práticas a partir 
da explicitação das condições de formação que possuem. Nesse sentido, é importante entender que:

Nenhuma formação docente verdadeira pode fazer-se alheada, de um lado, do exercício da criticidade que implica a promoção da curiosidade ingênua à curiosidade epistemológica, e do outro, sem o reconhecimento do valor das emoções, da sensibilidade, da afetividade, da intuição ou adivinhação. Conhecer não é, de fato, adivinhar, mas tem algo que ver, de vez em quando, com adivinhar, com intuir. O importante, não resta dúvida, é não pararmos satisfeitos ao nível das intuições, mas submetê-las à análise metodicamente rigorosa de nossa curiosidade epistemológica. (FREIRE, 1996, p.20)

Com base nessa convicção é que avançamos nossas análises na tentativa de apreender as percepções dos docentes universitários da área da saúde a respeito da importância dos processos de formação para sua prática profissional.

\section{Percepções dos docentes universitários da área da saúde a respeito da profissionalização docente}

Em pesquisa realizada com 25 docentes universitários, no campo de conhecimento das ciências biomédicas, traçamos o perfil deles visando à análise das suas percepções a respeito de questões que se encontram no bojo da atividade que exercem.

Do total desses 25 professores, dois ( $8 \%$ ) eram do curso de Biomedicina, três (12\%) eram do curso de Educação Física, nove (36\%) eram do curso de Fisioterapia e 11 (44\%) eram professores do curso de Psicologia.

Os docentes foram convidados a responder um questionário contendo dez questões de múltipla escolha. As questões apresentavam cinco opções e era solicitado que assinalassem apenas uma alternativa. As alternativas eram: nada importante, pouco importante, neutro, importante e muito importante.

As perguntas versavam sobre a importância de: 1) ter qualificação para atuar na docência universitária, com formação específica; 2) ter preocupação com o aperfeiçoamento pedagógico e a formação continuada; 3) saber refletir sobre o significado do saber pedagógico; 4) se capacitar por meio de titulação; 5) realizar cursos de formação específica para professores; 6) ter conhecimento da prática docente; 7) ter capacidade de refletir na prática profissional e sobre a prática docente; 8) saber estimular a perspectiva críticoreflexiva na formação dos alunos; 9) saber valorizar a prática pedagógica como elemento de construção de conhecimentos; 10) ter consciência da importância da formação pedagógica para o exercício da docência. 
Quanto à primeira questão que tratava sobre a importância de ter qualificação para atuar na docência universitária com formação específica, 4\% (1 respondente) dos docentes consideraram nada importante, $8 \%$ (2 respondentes) consideraram neutro, $28 \%$ (7 respondentes) consideraram importante e 60\% (15 respondentes) consideraram muito importante.

Na segunda questão que indaga aos docentes sobre a importância da preocupação com o aperfeiçoamento pedagógico e a formação continuada, $8 \%$ (2 respondentes) afirmaram que é importante e 92\% (23 respondentes) afirmaram ser muito importante.

$\mathrm{Na}$ terceira questão, que fazia menção à necessidade de saber refletir sobre o significado do saber pedagógico, 8\% (2 respondentes) acreditam ser neutro, 24\% (6 respondentes) acham que é importante e 68\% (17 respondentes) afirmaram ser muito importante.

Na quarta questão, que pergunta sobre a necessidade de capacitar-se por meio de titulação, para 60\% dos docentes é algo importante e $40 \%$ consideram como um item muito importante.

As respostas apresentadas na quinta questão, a respeito da necessidade de realizar cursos de formação específica para professores, 20\% acham que é neutro, 32\% acham que é importante e $48 \%$ acham que é muito importante.

A sexta questão, que indaga sobre a importância de ter conhecimento da prática docente, $12 \%$ dos professores acreditam ser neutro, $20 \%$ que é importante e $68 \%$ que acreditam ser muito importante.

Na sétima questão, que fez referência à importância de ter capacidade de refletir na prática profissional e sobre a prática docente, $28 \%$ afirmaram ser importante e $72 \%$ colocaram como muito importante.

$\mathrm{Na}$ oitava questão, em que se procurou verificar o grau de importância que os docentes atribuíam à necessidade de saber estimular a perspectiva crítico-reflexiva na formação dos alunos, $8 \%$ afirmaram ser neutro, para 20\% é algo importante e para $72 \%$ é muito importante.

A nona questão procurava investigar o nível de importância que os professores atribuíam ao saber valorizar a prática pedagógica como elemento de construção de conhecimentos, sendo que $8 \%$ avaliam como neutro, 36\% como importante e $56 \%$ como muito importante. E, por fim, ao indagar sobre o grau de importância da necessidade de ter 
consciência da importância da formação pedagógica para o exercício da docência, para 12\% é algo neutro, para $36 \%$ é importante e para $52 \%$ é muito importante.

Verifica-se que é praticamente senso comum o fato de que o professor deva ter domínio do conteúdo que ensina, pois diversos estudos - de Masetto (2003), corroboram essa afirmação. Nesta pesquisa, duas questões puderam confirmar essa assertiva. Na primeira, $88 \%$ dos docentes consideraram "importante" ou "muito importante" ter qualificação para atuar na docência universitária com formação específica (não houve diferenças significativas entre os cursos). Na segunda, todos os respondentes (100\%) consideraram "importante" ou "muito importante" a capacitação por meio de titulação.

A preocupação com a formação pedagógica também parece estar ganhando espaço entre os docentes. Ao serem questionados sobre ter preocupação com o aperfeiçoamento pedagógico e a formação continuada, todos os docentes atribuíram importância à questão. Quando questionados sobre a consciência da importância da formação pedagógica para o exercício da docência, novamente houve alto percentual de respostas (88\%) às categorias "importante" e "muito importante". A quinta questão abordava a realização de cursos de formação específica para professores. Sobre esse aspecto, 80\% dos docentes consideram-no "importante" ou "muito importante".

A prática pedagógica é outro ponto importante na docência. Os saberes experienciais são discutidos por vários autores, tais como Imbernón (2004), Pimenta (2002, Tardif (2002). Para Freire (1996, p. 22), "a reflexão crítica sobre a prática se torna uma exigência da relação Teoria/Prática sem a qual a teoria pode ir virando proselitismo e a prática, ativismo”.

Sobre a prática pedagógica também havia três questões. A primeira versava sobre o conhecimento da prática pedagógica, sendo que para $88 \%$ dos pesquisados tal conhecimento é "importante" ou "muito importante". A segunda questão estava relacionada à valorização da prática pedagógica como momento de construção de conhecimentos. Novamente o percentual de docentes que a consideraram "importante" ou "muito importante" foi elevado: $92 \%$. A terceira pergunta era sobre a capacidade de refletir na prática profissional a prática docente. Para os docentes, essa reflexão também é relevante, pois todos eles (100\%) marcaram as opções "importante" ou "muito importante".

Ainda sobre o processo reflexivo foram feitas duas últimas perguntas. Questionados sobre a importância de saber refletir sobre o significado do saber pedagógico, $92 \%$ dos docentes consideraram-no "importante" ou "muito importante". Finalmente, 92\% dos professores consideram "importante" ou "muito importante" saber estimular a perspectiva 
crítico-reflexiva na formação dos alunos. É animadora a valorização dessa questão por parte dos docentes que atuam na área de saúde. Isso porque várias questões éticas permeiam a profissão docente e, em especial, na área de saúde, torna-se mais aparente devido ao fato de que todos lidam com seres humanos e a preocupação em manter a integridade deles deve ser repassada e experienciada por docentes e discentes.

Ainda que haja a tendência de valorizar o campo de pesquisa em detrimento da docência no ensino superior, a correlação entre essas duas práticas é condição sine qua non para a constituição da profissão na sua totalidade. Assim: “A capacidade de aprender, não apenas para nos adaptar, mas, sobretudo para transformar a realidade, para nela intervir, recriando-a, fala de nossa educabilidade a um nível distinto do nível do adestramento dos outros animais ou do cultivo de plantas" (FREIRE, 1996, p.65) Trata-se aqui do que Freire (1996) analisa como a apreensão da substantividade do objeto.

Enfim, embora uma pequena parcela ainda não tenha conseguido perceber a importância das questões trabalhadas no questionário, podemos dizer que, de modo geral, a maioria dos docentes universitários da área pesquisada estão cientes da necessidade de formação para a docência, que não seja constituída numa perspectiva unilateral ou que compreenda apenas uma competência específica de sua área ou uma competência pedagógica. O reconhecimento da necessidade em se valorizar a formação enquanto elemento que compreende os seres humanos com suas capacidades gnosiológicas, enquanto seres inacabados e em constante construção, é o que promove a construção do profissional docente numa dimensão ética, reflexiva e humana.

Somos otimistas quanto às respostas apresentadas pelos participantes da pesquisa. A compreensão de que a docência no ensino superior é algo mais complexo do que o simples "ensinar se aprende ensinando" denota uma conscientização acerca do fato de que, em tempos de pós-neoliberalismo, as exigências para a formação profissional encontram-se mais complexas e determinadas por condições que vão além dos saberes técnicos e que a atuação em sala de aula depende de uma formação adequada e continuada. No entanto, apenas essa conscientização não é o suficiente. É necessário que haja uma responsabilização de todos envolvidos no processo de construção do conhecimento: professores, instituição e, em especial, o poder público. Em especial porque as políticas voltadas para a formação dos profissionais da educação são muito frágeis e inconsistentes, o que dá margem a diversas interpretações equivocadas e permeadas pela subjetividade. 


\section{Considerações finais}

Sob o pressuposto de que a formação profissional docente se reflete e se molda segundo a preponderância do contexto sócio-político-econômico que o indivíduo está inserido, este artigo foi estruturado tendo como ponto de partida a caracterização dos contextos neoliberal e pós-neoliberal e seus desdobramentos nas políticas educacionais para o ensino superior. Foi inserindo em um contexto macro os resultados de uma pesquisa sobre as percepções dos docentes universitários a respeito de questões que envolvem a formação específica, pedagógica e crítico-reflexiva para a atividade docente.

Constata-se, assim, a existência, no contexto neoliberal, de uma relação entre o papel dos organismos internacionais e a forma como as agendas de políticas se constituem. Nesse contexto, a modernização da educação é identificada com a profissionalização e a diminuição do papel do Estado, a partir das condicionalidades provenientes de instituições como o Banco Mundial, FMI e o BID, os quais impõem o controle mais direto sobre o curriculum e a avaliação docente; a redução dos custos em educação por parte dos governos e com pressão dos "clientes" em termos de uma escola gerencialista.

Por outro lado, a ascensão dos governos pós-neoliberais representou uma postura de reflexão ao papel a ser desenvolvido pelo Estado na economia e na política, proporcionando uma revisão das estratégias políticas domésticas e internacionais. Esse papel, designado "neodesenvolvimentista", atribui ao Estado a capacidade pela estabilidade econômica, afastando a ideia de predomínio do mercado para determinar os rumos do desenvolvimento. Contudo, nesse contexto, o papel do Estado oscilou entre a presença proeminente do pensamento desenvolvimentista, o afastamento ilusório do neoliberalismo e ao papel da associação entre Estado e sociedade. No Brasil, as escolhas políticas pós-neoliberais do governo Lula da Silva (2003-2010) e Dilma Rousseff I (2011-2014) representaram uma forte mudança na postura e no papel desempenhado pelo Estado.

Apesar disso, eles ainda não foram capazes de apresentar, de maneira clara, a desconstrução do modelo neoliberal. Isso porque continuou à mercê de orientações de organismos internacionais como o Banco Mundial e do Banco Interamericano de Desenvolvimento. Nesses organismos, os debates da profissionalização docente repousam na ideia de uma profissionalização concentrada na competência técnica e numa avaliação de que 
a autonomia das instituições deve estar cerceada por políticas que penalizem trabalhadores de baixo desempenho profissional e estimulem a recompensas aos profissionais que prestam um serviço de excelência.

Assim, instaura-se o desenvolvimento de uma autonomia administrativa, na qual o governo transfere a autonomia decisória dos investimentos à instituição, que juntamente com os docentes relacionam-se diretamente no controle e alocação dos recursos escolares, assim como a busca por uma autonomia pedagógica, presumindo que tal fato irá incidir positivamente sobre os resultados educativos.

Dessa forma, vemos indícios claros que caracterizam uma não ruptura pós-neoliberal, mas uma "continuidade encoberta do neoliberalismo de 1990", absorvendo as diretrizes de profissionalização docente disseminadas pelos organismos internacionais criados no contexto neoliberal.

Temos, portanto, por conclusão, que a formação do docente não deve ser encarada de forma unilateral, considerando apenas os aspectos técnicos, mas também deve haver o reconhecimento das condições sociais de trabalho e formação docente. Isso requer uma formação capaz de colocar o futuro docente universitário em contato com a realidade educacional propriamente, possibilitando uma visão mais ampla dos processos educativos no ensino superior.

\section{Referências}

AGUIAR, Vilma. Um balanço das políticas do governo Lula para a Educação Superior: Continuidade e Ruptura. Revista de Sociologia e Política, v.24, n.57, p. 113-126, março, 2016. ISSN: $1678-9873$.

BATISTA, Eliane Regina Martins. Políticas de Formação para o Professor do Ensino Superior. $2011 . \quad$ Disponível em: <http://www.anpae.org.br/simposio2011/cdrom2011/PDFs/trabalhosCompletos/comunic acoesRelatos/0160.pdf> Acesso em: 24 mai. 2016.

BRASIL. Constituição da República Federativa do Brasil. Brasília: Senado Federal, 1988. Disponível em:<http://www.planalto.gov.br/ccivil_03/constituicao/constituicaocompilado.htm> Acesso em: 22 mai. 2016

Lei de Diretrizes e Bases da Educação Nacional Nº 9.394/96. Brasília, DF. Disponível em: <http://www.planalto.gov.br/ccivil_03/leis/L9394.htm> Acesso em: 24 mai. 2016. 
CERVO, Amado Luiz; BUENO, Clodoaldo. História da Política Exterior do Brasil. Brasília: Editora: UnB, 525 p., 2014. ISBN: 8523012877

CERVO, Amado Luiz. Inserção Internacional: Formação dos Conceitos Brasileiros. Editora: Saraiva, p. 297, 2008. ISBN: 9788592965703

DASSOLER, Olmira; LIMA, Denise. A formação e a profissionalização docente: características, ousadia e saberes. IX ANPED SUL. Seminário de Pesquisa em Educação da Região Sul, 2012. ISSN: 2236-5729

FACCI, M. G. Fazendo um "Recorte": A compreensão da profissão docente a partir da década de 1980. In: FACCI, M. G. D. Valorização ou esvaziamento do trabalho do professor? Um estudo crítico-comparativo da teoria do professor reflexivo, do construtivismo e da psicologia vigotskiana. Campinas, SP: Autores Associados, 2004. ISBN: 85-7496-103-5.

FREIRE, Paulo. Pedagogia da Autonomia: saberes necessários à prática educativa. São Paulo: Paz e Terra, 1996. ISBN: 85-2 19-0243-3.

IMBERNÓN, Francisco. Formação Docente e Profissional: Formar-se para a mudança e a incerteza. $4^{\mathrm{a}}$ edição. São Paulo: Cortez, 2004. ISBN: 85-2491-630-3.

KIMURA, Patrícia R. O.; FRANÇA, Rita C. C. R.; NASCIMENTO, Ivany P.; COELHO, Vilma. N. B. Caminhos da formação e profissionalização docente no Brasil: Desafios e Perspectivas na contemporaneidade. Revista Reflexão e Ação, Santa Cruz do Sul, vol. 20, n1, p. 09-23, jan. /jun., 2012. ISSN: 1982-9949

MALUSÁ, Silvana. O docente, o sistema socioeconômico atual, a ética, e os desafios à educação. Revista de Educação do Congeime. Ano 10, nº18. Jun. 2001. ISSN: 2358-9280.

MASETTO, M. T. Professor Universitário: um profissional da educação na atividade docente. In: MASETTO, M. T. (Org.). Docência na Universidade. $6^{\mathrm{a}}$ ed. Campinas, SP: Papirus, 2003. ISBN 85-308-0509-7.

NÓvOA, Antonio. Formação de professores. Lisboa (Portugal): Do Quixote, 1995 ISBN: 97203-4103-3.

PENA, Rodolfo F. Alves. Consenso de Washington; Brasil Escola. Disponível em <http://brasilescola.uol.com.br/geografia/consenso-washington.htm>. Acesso em 22 de junho de 2016.

PIMENTA, Selma; ANASTASIOU, Léa das Graças Camargos. Docência no ensino superior. São Paulo: Cortez, 2002. ISBN: 85-249-0857-2.

SADER, Emir (Org.). 10 Anos de governos pós-neoliberais no Brasil: Lula e Dilma. Editora: Flacso Brasil, 2013, 384p. ISBN 978-85-7559-328-8

TARDIF, M. Saberes docentes e formação profissional. Petrópolis, RJ: Vozes, 2002. ISBN: 85326-4428-2.

TELLO, Cesar; ALMEIDA, Maria de L. P. Políticas educativas e profissionalização docente na América Latina. Revista Lusófona de Educação, 26, p. 161-174, 2014. ISSN: 1646-401X. 
TELLO, Cesar; MAINARDES, Jefferson. Políticas docentes na América Latina: entre o neoliberalismo e o pós-neoliberalismo. In Romilda Teodora Ens., Lúcia Villas Boas, Marilda Aparecida Behrens (Org.). In: Espaços educacionais: das políticas docentes à profissionalização. Edição 1, Ed. PUCPress, p. 31-62, 2015. ISBN 978-85-68324-13-4.

\footnotetext{
i O Consenso de Washington foi a forma como ficou popularmente reconhecida uma reunião de autoridades e países neoliberais ocorrida em 1989, na capital dos Estados Unidos. Nesse encontro, realizou-se uma série de recomendações visando ao desenvolvimento e à ampliação do neoliberalismo nos países da América Latina. Essa reunião foi convocada pelo Institute for International Economics, sob o nome de "Latin Americ Adjustment: Howe Much has Happened?', e envolveu instituições e economistas de perfil neoliberal, além de alguns pensadores e administradores de países latino-americanos. Cf. PENA, Rodolfo F. Alves. "Consenso de Washington"; Brasil Escola. Disponível em <http://brasilescola.uol.com.br/geografia/consensowashington.htm>. Acesso em 22 de junho de 2016.
} 